\title{
DSpace@MIT
}

\author{
MIT Open Access Articles
}

\section{Examination on Time-Dependent Soil Models in One-Dimensional Consolidation}

The MIT Faculty has made this article openly available. Please share how this access benefits you. Your story matters.

Citation: Yuan, Yixing, and Andrew J. Whittle. “Examination on Time-Dependent Soil Models in One-Dimensional Consolidation." Springer Series in Geomechanics and Geoengineering (2013): 159-166.

As Published: http://dx.doi.org/10.1007/978-3-642-32814-5_18

Publisher: Springer-Verlag

Persistent URL: http://hdl.handle.net/1721.1/92765

Version: Author's final manuscript: final author's manuscript post peer review, without publisher's formatting or copy editing

Terms of use: Creative Commons Attribution-Noncommercial-Share Alike 


\title{
EXAMINATION ON TIME-DEPENDENT SOIL MODELS IN ONE-DIMENSIONAL CONSOLIDATION
}

\author{
Yixing Yuan* and Andrew J. Whittle \\ Department of Civil and Environmental Engineering \\ Massachusetts Institute of Technology, Cambridge, MA 02139 \\ *e-mail: Yixing@mit.edu
}

\begin{abstract}
This paper reviews the performance of two time-dependent constitutive models in predictions of one-dimensional consolidation. The Soft-Soil Creep model [1] is an example of an elastic-viscoplastic formulation that incorporates a timedependent state variable to estimate viscoplastic deformation. We show that the SSC model is equivalent to the isotache formulation proposed by Imai [2], as both are based on a unique relationship between stress, void ratio and the viscoplastic component of void ratio rate. Simulations of 1-D consolidation confirm that both models represent Hypothsis B behavior, where the axial strain at the End of Primary (EOP) consolidation is dependent on the depth of the clay layer. The effects of specimen thickness and the phenomenon of pore pressure increase at the start of consolidation are discussed in detail. Our interpretation highlights the importance of assumptions regarding the initial strain rate on the behavior observed at different scales under a given applied increment of loading.
\end{abstract}

Keywords: elastic-viscoplastic, isotache, thickness effect, initial strain rate.

\section{INTRODUCTION}

There are many formulations that have been developed to explain the interactions between creep and consolidation behavior of clays that affect the time dependent response at different length scales. In this paper we show that the viscoplastic formulation used for the Soft-Soil Creep model (SSC; [1]) is equivalent to the Isotache framework proposed by Imai [2]. Isotache concepts can then be used to interpret to predictions using the SSC model.

\section{EQUIVALENCE OF SSC AND ISOTACHE FORMULATIONS}

Fig.1 shows a schematic representation of the SSC model for 1-D loading.. This model describes the deformation of soil skeleton as a combination of elastic 
$\Delta \mathrm{e}^{\mathrm{e}}$ and viscoplastic components $\Delta \mathrm{e}^{\mathrm{vp}}$ (Table 1, Eqn. a1). The elastic part is controlled by the swelling index, $\mathrm{C}_{\mathrm{s}}$ (Eqn. a2), while the viscoplastic part corresponds to creep deformation governed by the secondary compression coefficient, $\mathrm{C}_{\alpha}$. Due to the difficulties of measuring the duration of creep, the SSC model uses a timedependent state parameter $\sigma_{\mathrm{p}}$, which is defined as the projection of the current effective stress $\sigma^{\prime}$ onto a reference-time line $\left(\tau_{\text {ref }}\right.$ line, Fig.1.) following the sediment ageing framework of Bjerrum [3]. The rate of viscoplastic deformation is a function of the ratio of $\sigma^{\prime}$ over $\sigma_{p}$ (Eqn. a3). The parameter $\sigma_{p}$ is updated as the accumulation of creep over time (Eqn. a4). The SSC model requires four material constants, the virgin compression index $\mathrm{C}_{\mathrm{c}}$, the swelling index $\mathrm{C}_{\mathrm{s}}$, the secondary compression coefficient $\mathrm{C}_{\alpha}$, and the reference time, $\tau_{\text {ref }}$, together with the intial value of the state variable, $\sigma_{\mathrm{p} 0}$.

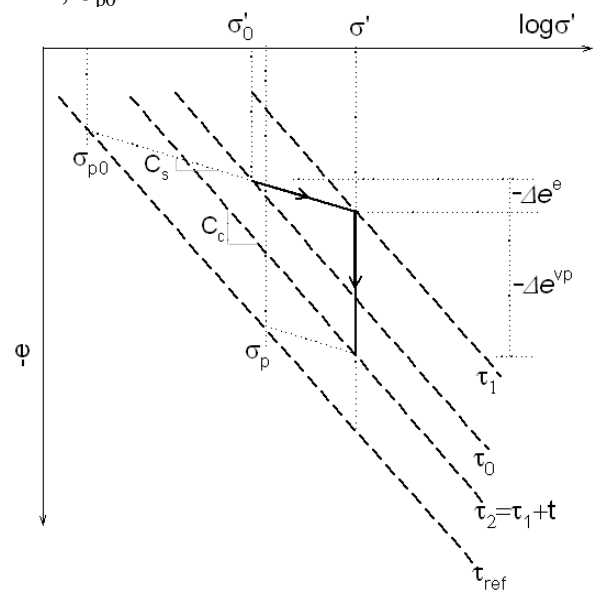

Fig. 1. Framework of Soft-Soil-Creep model under 1D loading (after Vermeer and Neher [1])

Table 1. Equations of SSC and Imai's Isotache formulation

\begin{tabular}{cccc}
\hline SSC Model [1] & Isotache Model [2] & \\
\hline$\dot{e}=\dot{e}^{e}+\dot{e}^{v p}$ & (a1) & $\dot{e}=\dot{e}^{r}+\dot{e}^{i r}$ & (b1) \\
\hline$\dot{e}^{e}=-0.434 C_{s} \frac{\dot{\sigma}^{\prime}}{\sigma^{\prime}}$ & (a2) & $\dot{e}^{r}=-0.434 C_{s} \frac{\dot{\sigma}^{\prime}}{\sigma^{\prime}}$ & (b2) \\
\hline$\dot{e}^{v p}=-0.434 \frac{C_{\alpha}}{\tau_{r e f}}\left(\frac{\sigma^{\prime}}{\sigma_{p}}\right)^{\frac{C_{c}-C_{s}}{C_{\alpha}}}$ & (a3) & $e+C_{c} \log \sigma^{\prime}=\Gamma=C_{\alpha} \log \left(-\dot{e}^{i r}\right)+b$ & (b3) \\
\hline$\sigma_{p}=\sigma_{p 0} \exp \left[\frac{-\Delta e^{v p}}{0.434\left(C_{c}-C_{s}\right)}\right]$ & (a4) & $\dot{e}^{i r}=-10^{\left(e+C_{c} \log \sigma^{\prime}-b\right) / C_{\alpha}}$ & (b4) \\
\hline
\end{tabular}

Fig. 2a shows the framework of the Isotache model proposed by Imai [2]. Each isotache line is defined by a specifed value of $\Gamma\left(=\mathrm{e}+\mathrm{C}_{\mathrm{c}} \log \sigma^{\prime}\right)$, where $\Gamma$ is a function of the void ratio rate $(-\dot{e})$. There is a unique linear relationship of $\Gamma(=a \log (-$ è) + b), after "apparent yield" (Fig.2b).

Imai [2] assumed that if the total void ratio rate can be separated into recovera- 
ble $\left(-\dot{e}^{r}\right)$ and irrecoverable components (- $\left.\dot{e}^{\text {in }}\right)$, a unique linear relationship also holds between $\left(-\dot{e}^{\text {ir }}\right)$ and $\Gamma$. This results is expressed by $\Gamma=a \log \left(-\dot{e}^{\text {ir }}\right)+b$ with slope $C_{\alpha}$. This relationship can be verified particularly with the data after the End-OfPrimary consolidation (EOP), as the void ratio rate (-è) reduces to the irrecoverable rate $\left(-\dot{e}^{\text {ir }}\right)$ in secondary compression. Imai's assumption also holds well within the range of primary consolidation as long as the irrecoverable component is dominant in overall deformation (e.g., after "apparent yield").

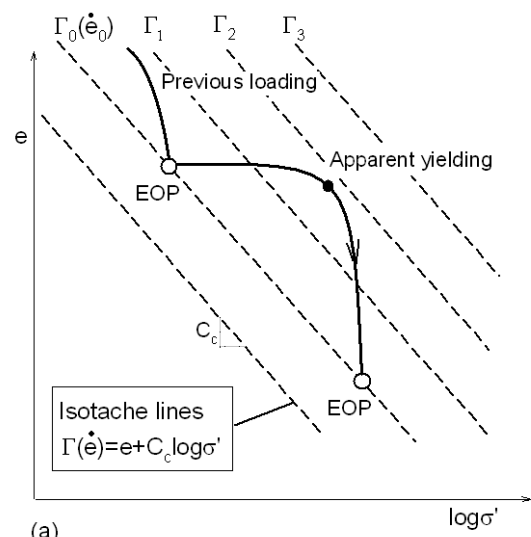

(a)

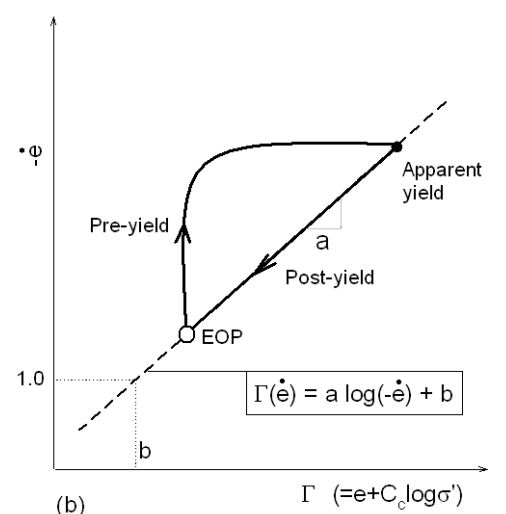

(b)

Fig. 2. Schematic representation of Imai's model [2]: (a) isotaches; (b) isotache-void ratio rate

Table 1 lists the equations of Imai's Isotaches formulation. Equation b1 shows the separation rule that is essentially equivalent to the SSC model, if $\left(-\dot{e}^{r}\right)=\left(-\dot{e}^{e}\right)$ and $\left(-\dot{e}^{\mathrm{i}}\right)=\left(-\dot{\mathrm{e}}^{\mathrm{vp}}\right)$. Although the recoverable void ratio is of the same form as SSC (Eqn. b) Equation b2 (vs a2), the irrecoverable component (- $\left.\mathrm{e}^{\mathrm{ir}}\right)$ is obtained through a unique geometric relationship presented in Eqn.b3. In summary, this Isotache model requires four input parameters $\mathrm{C}_{\mathrm{c}}, \mathrm{C}_{\mathrm{s}}, \mathrm{C}_{\alpha}$, and b (Fig. 2b).

In order to find the relation between Imai's model and SSC, the parameter $\mathrm{b}$ in the Isotaches formulation is expressed with initial condition as

$$
b=e_{0}+C_{c} \log \sigma_{0}^{\prime}-C_{\alpha} \log \left(-\dot{e}_{0}^{i r}\right)
$$

where $\mathrm{e}_{0}, \sigma_{0}$ ' and $\left(-\dot{\mathrm{e}}_{0}{ }^{\text {ir }}\right)$ are initial void ratio, effective stress and irrecoverable void ratio rate, respectively. Substituting Eq. 3.1 into Eq. b3, and subtracting the recoverable component $\left(-\Delta \mathrm{e}^{\mathrm{r}}=\mathrm{C}_{\mathrm{s}} \log \left[\sigma^{\prime} / \sigma_{0}^{\prime}\right]\right)$ from the total void ratio change of ($\Delta \mathrm{e}=\mathrm{e}_{0}-\mathrm{e}$ ), we obtain the irrecoverable component of void ratio change as:

$$
-\Delta e^{i r}=\left(C_{c}-C_{s}\right) \log \frac{\sigma^{\prime}}{\sigma_{0}^{\prime}}-C_{\alpha} \log \frac{-\dot{e}^{i r}}{-\dot{e}_{0}^{i r}}
$$

Combining Eqns. 3.2 and $\mathrm{a} 4$, and assuming $\left(-\Delta \mathrm{e}^{\mathrm{vp}}\right)=\left(-\Delta \mathrm{e}^{\mathrm{ir}}\right)$, we have an expression of $\left(-\dot{e}^{\text {ir }}\right)$ :

$$
-\dot{e}^{i r}=\left[\left(-\dot{e}_{0}^{i r}\right)\left(\frac{\sigma_{p 0}}{\sigma_{0}^{\prime}}\right)^{\frac{C_{c}-C_{s}}{C_{\alpha}}}\right]\left(\frac{\sigma^{\prime}}{\sigma_{p}}\right)^{\frac{C_{c}-C_{s}}{C_{\alpha}}}
$$


Through the geometric relation of Isotaches, one can show the first term on the right hand side of Eqn. 3.3 maps the initial irrecoverable void ratio rate $\left(-\dot{e}_{0}{ }^{i r}\right)$ to a reference void ratio rate $\left(-\dot{\mathrm{e}}_{\text {ref }}\right)=0.434\left(\mathrm{C}_{\alpha} / \tau_{\text {ref }}\right)$. Eqn. 3.3 for the Isotache model is then same as SSC model Eqn. a3 and hence, the two formulations are equivalent. We can easily convert the SSC parameters $\tau_{\text {ref }}$ and $\sigma_{\mathrm{p} 0}$ with the Isotache parameter b by using Eqn. 3.1 together with

$$
-\dot{e}_{0}^{i r}=\frac{0.434 C_{\alpha}}{\tau_{r e f}}\left(\frac{\sigma_{0}^{\prime}}{\sigma_{p 0}}\right)^{\frac{C_{c}-C_{s}}{C_{\alpha}}}
$$

The equivalency between SSC and Imai's model implies these two models are based on the same unique relationship among stress, void ratio, and irrecoverable void ratio rate, as indicated in Eqn. b3.

\section{SIMULATION OF ONE-DIMENSIONAL CONSOLIDATION}

Numerical analyses of one-dimensional consolidation are conducted to simulate incremental oedometer tests using the SSC and Isotache models. The differential equations of coupled consolidation are solved using a finite difference method (similar to [8]). The analyses also account for nonlinear variations of hydraulic conductivity with void ratio. The total strain rate is controlled by the distribution of excess pore pressure, whereas the constitutive model determines the viscoplastic (irrecoverable) deformation and the changes in effective stress.

Example calculations have been performed using input parameters corresponding to Yokohama clay (following the calibration of the Isotache model by Hawlader et al. [5]), Table 2. The initial example considers a normally consolidated specimen, with $\sigma_{0}{ }_{0}=160 \mathrm{kPa}$ and $\mathrm{e}_{0}=2.38$, with zero initial excess pore pressure that is subject to an incremental load, $\Delta \sigma=160 \mathrm{kPa}$ and consolidates with top drainage only. Since we assume that the specimen is normally consolidated, the SSC state variable $\sigma_{\mathrm{p} 0}=\sigma^{\prime}{ }_{0}$ and the reference time $\tau_{\text {ref }}$ is determined as $24 \mathrm{hr}$ using Eqns. 3.1 and 3.4. It should be noted that the parameter $\mathrm{b}$ is not dimensionless, but should be consistent with the stress and time units ([kPa] and [hr] in this case).

Table 2. Model input parameters for Yokohama clay (after [5])

\begin{tabular}{cccccccc}
\hline $\begin{array}{c}\mathrm{k}_{0} \\
{[\mathrm{~cm} / \mathrm{hr}]}\end{array}$ & $\mathrm{C}_{\mathrm{k}}$ & $\mathrm{C}_{\mathrm{c}}$ & $\mathrm{C}_{\mathrm{s}}$ & $\mathrm{C}_{\mathrm{a}}$ & $\mathrm{b}^{*}$ & $\begin{array}{c}\tau_{\mathrm{ref}} * * \\
{[\mathrm{hr}]}\end{array}$ & $\begin{array}{c}\sigma_{\mathrm{p} 0} * * \\
{[\mathrm{kPa}]}\end{array}$ \\
\hline $2.66 \times 10^{-4}$ & 1.8 & 1.05 & 0.11 & 0.05 & 4.85 & 24 & 160 \\
\hline
\end{tabular}

* Isotache model; **SSC model

Note: $\left(e-e_{0}\right)=C_{k} \log \left(k_{v} / k_{v 0}\right)$

Fig. 3 shows that consolidation curves from SSC and the Isotache model match perfectly for specimens with thickness, $\mathrm{H}=3.5 \mathrm{~cm}$ and $35 \mathrm{~cm}$. Both models describe creep occurring concurrently with primary consolidation and hence, predict larger changes in void ratio at the EOP condition for the thicker specimen, consistent with Hypothesis B [6]. 


\section{THICKNESS EFFECTS}

Fig. 4 shows the variation of the normalized base pore pressure $\left(\mathrm{u}_{\mathrm{b}} / \Delta \sigma\right)$ predicted by the $\mathrm{SSC}$ model for cases with $\mathrm{H}=3.5 \mathrm{~cm}$ and $35 \mathrm{~cm}$ for the initial conditions, material parameters and incrmenta load conditions $(160-320 \mathrm{kPa})$ described above. Results for the thin specimen $(3.5 \mathrm{~cm})$ show a monotonically decrease in base pore pressure. In contrast, for $\mathrm{t} \leq 0.5$ days there is a small increase in $\mathrm{u}_{\mathrm{b}}$ at the base of the thicker specimen $(35 \mathrm{~cm})$ prior to dissipation.

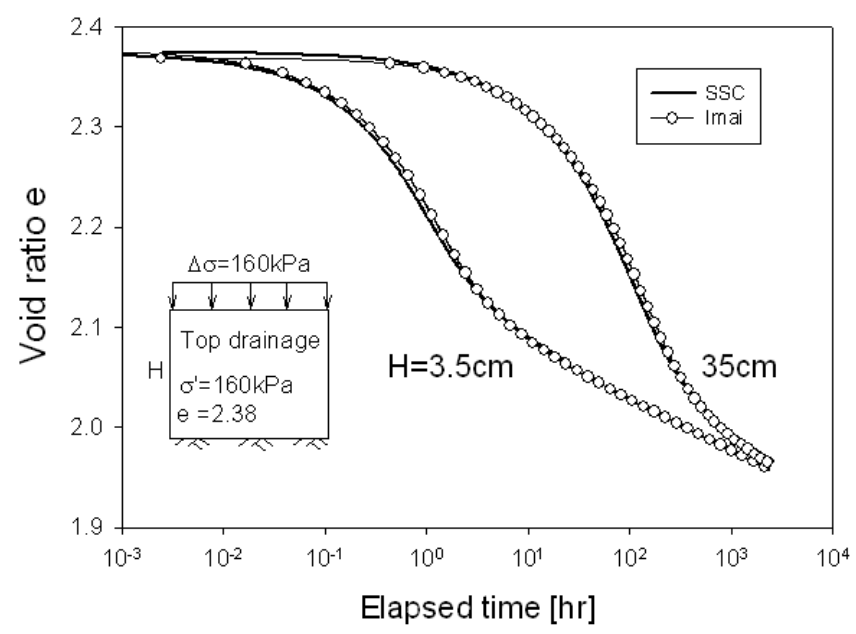

Fig. 3. Variation of void ratio from simulations with SSC and Imai's model for two different drainage heights: $3.5 \mathrm{~cm}$ and $35 \mathrm{~cm}$

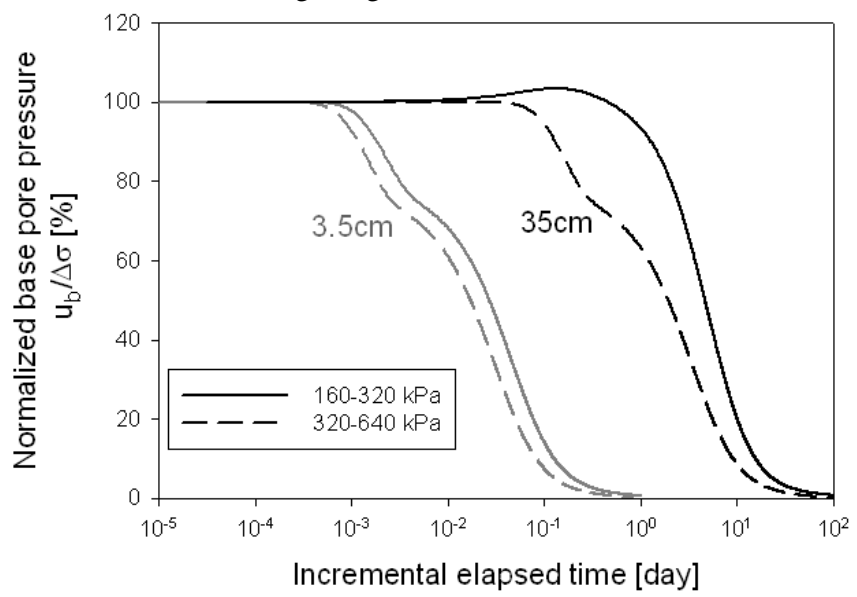

Fig. 4. Variation of normalized base pore pressure for specimens with different drainage heights under two increments of load

Stolle et al. [7] have found similar behavior using the SSC model.. Yin and 
Graham [8] attribute this behavior to undrained creep that occurs far from the drainage boundary. During undrained creep, the accumulation of viscoplastic strain must be compensated by a reduction in effective stress and hence, to an increase in pore pressure. However, we view this phenomenon differently. It is interesting to note that all prior simulations assume that the initial pore pressures are equal to zero. This assumption is apparently inherited from the Terzaghi consolidation theory, in which the pore pressures become negligible after EOP. This assumption implies no gradient across the specimen and hence, zero strain rate everywhere. However, in reality fully consolidated soil still undergoes secondary compression where the total strain rate is non-zero and is equal to the irrecoverable strain rate due to creep. This important implication from the Isotache formulation is often overlooked in predictions with elastic-viscoplastic models. Therefore, the increase in pore pressure is due to an inconsistency between the initial total strain and viscoplastic strain rates, but is not an intrinsic characteristic of normally consolidated soil.

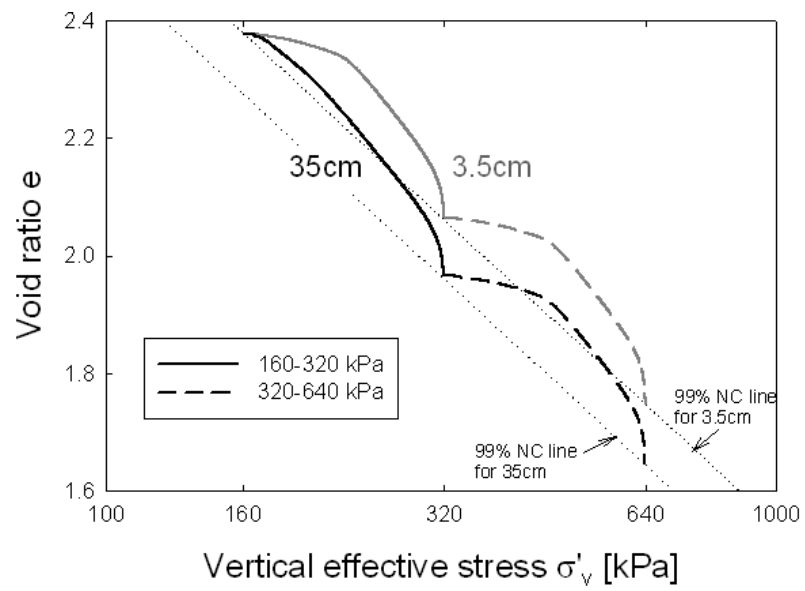

Fig. 5. Void ratio-stress paths of consolidating specimens with different heights under two increments of load

In order to demonstrate this fact, specimens are firstly consolidated up to $99 \%$ pore pressure dissipation under the first increment of load from 160 to $320 \mathrm{kPa}$. A subsequent load increment is applied from $320 \mathrm{kPa}$ to $640 \mathrm{kPa}$. Fig. 4 also compares the normalized variations in base pore pressure for this second load increment. In this case, qualitatively similar behavior occurs for both $\mathrm{H}=3.5 \mathrm{~cm}$ and $35 \mathrm{~cm}$ specimens. This result occurs because at the end of the first increment, the pore pressure gradient produces sufficient total strain rate to balance the viscoplastic strain rate. There is no undrained creep after the second load increment is applied.

More results can be extracted from the two successive increments of loading: Fig. 5 plots the void ratio-effective stress relations. In the first load increment, the thin and thick specimens start with the same initial effective stress and void ratio, 
and are initially on the same Isotache. The thicker specimen tends consolidates for a longer period of time and produces more deformation than the thin specimen at EOP. In the second load increment, the two specimens start different EOP conditions, (i.e., they are initially on Isotaches with different initial strain rates), as shown in Fig. 5. However, if one plots the incremental change in void ratio for the two specimens during this second load increment, as shown in Fig.6, the two compression curves are almost parallel to each other. Although this result initially appears to conform to Hypothesis A behavior (as suggested in [9]), this is misleading as the initial void ratios of thin and thick specimens are different at the start of the load increment.

These results highlight that predictions using the SSC model vary significantly with the initial strain rate (this finding has also been noted by Degago et al. [10]). In this case we face a dilemma in using SSC to predict field consolidation. For instance, one often calibrates the model based on the experiment results and uses the obtained parameters to predict the field behavior. This procedure relies on the resemblance between the laboratory and the field. However, the initial strain rate in the field will generally differ from the one calibrated in laboratory tests. This difference will eventually cause discrepancies in predictions of consolidation behavior at field scale.

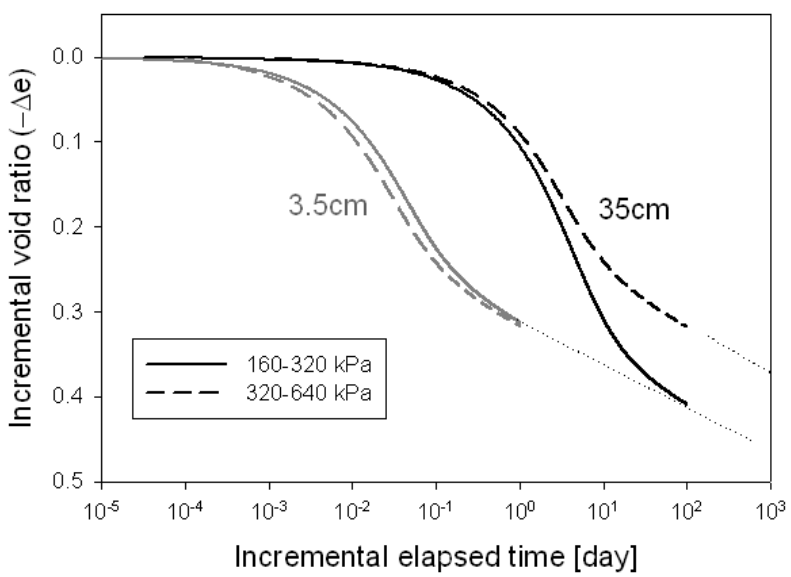

Fig. 6. Different relations of incremental void-ratio over time along two continuous increments

\section{CONCLUDING REMARKS}

In this paper, we show the formulations of two time-dependent soil models: SSC and Imai's Isotaches model are equivalent. The relationships are developed so that the parameters of two models can be converted from each other. Numerical simulations of one-dimensional consolidation are conducted on normally consolidated Yokohama clay. Two models predict very consistent results, and both are classified as Hypothesis B type models. 
Analyses of consolidation under incremental loads using the SSC model generate increases in pore pressures at constant total stress for thick specimens. Using the Isotache framework we show that this is due to an inconsistency between total and viscoplastic strain rates and can be eliminated in a subsequent load increment when the two strain rates are in equilibrium at the end of the first increment. In this case, the initial conditions for thin and thick specimens are the same in the first increment, but are different in the second increment. The resulting discrepancy between the compression behavior in the two load increments highlights the importance of the assumption of initial strain rate and has important impacts on the application of viscoplastic modles (such as SSC) for predicting consolidation at field scale.

\section{REFERENCES}

[1] Vermeer, P. A., and Neher, H. P.: A soft soil model that accounts for creep. Beyond 2000 in computational geotechnics: 10 years of PLAXIS International, proceedings of the International Symposium beyond 2000 in Computational Geotechnics. Amsterdam, The Netherlands, 1820 March 1999, 249 (1999)

[2] Imai, G.: Analytical examinations of the foundations to formulate consolidation phenomena with inherent time-dependence. Compression and consolidation of clayey soils, 891-935 (1995)

[3] Bjerrum, L.: Engineering geology of Norwegian normally consolidated marine clays as related to settlements of buildings. Géotechnique 17(2), 83-118 (1967)

[4] Yin, J. H., and Graham, J.: Elastic-viscoplastic modeling of one-dimensional consolidation. Géotechnique 46(3), 515-527 (1996)

[5] Hawlader, B. C., Muhunthan, B., and Imai, G.: Viscosity Effects on One-Dimensional Consolidation of Clay. International Journal of Geomechanics 3(1), 99 (2003)

[6] Ladd, C. C., Foott, R., Ishihara, K., Schlosser, F., and Poulos, H.: Stress-Deformation and Strength Characteristics. Proc. 9th Int. Conf. Soil Mechn. Fdn. Engng, Tokyo, 421-494 (1977)

[7] Stolle, D. F. E., Vermeer, P. A., and Bonnier, P. G.: A consolidation model for a creeping clay. Canadian Geotechnical Journal 36(4), 754-759 (1999)

[8] Yin, J. H., Graham, J., Clark, J. I., and Gao, L.: Modelling unanticipated pore-water pressures in soft days. Canadian Geotechnical Journal 31(5), 773-778 (1994)

[9] Imai, G., and Tang, Y.: A constitutive equation of one-dimensional consolidation derived from inter-connected tests. Soils and foundations 32(2), 83-96 (1992)

[10] Degago, S., Grimstad, G., and Jostad, H.: Use and misuse of the isotache concept with respect to creep hypotheses A and B. Géotechnique (10), 897-908 (2011) 